\title{
Do we still need autopsy in times of modern multislice computed tomography?-Missed diagnoses in the emergency room
}

\author{
S. A. Euler ${ }^{1}$ T. Kastenberger ${ }^{1} \cdot$ R. Attal ${ }^{1} \cdot$ M. Rieger $^{2} \cdot$ M. Blauth ${ }^{1}$. \\ M. Petri ${ }^{3}$
}

Received: 6 June 2016/Published online: 8 November 2016

(c) The Author(s) 2016. This article is published with open access at Springerlink.com

\begin{abstract}
Introduction In spite of increasing quality of emergency room (ER) assessment in trauma patients and improved accuracy of modern multislice computed tomography (MSCT), the number of potentially missed diagnoses is still controversial. The aim of this study was to compare the initial findings of ER assessment and MSCT to the findings during autopsy in trauma patients not surviving the first $48 \mathrm{~h}$ after admission. We hypothesized that autopsy was more accurate than MSCT in diagnosing potentially fatal diagnoses.
\end{abstract}

Patients and methods Between January 2004 and September 2007, all trauma patients undergoing ER treatment in our institution who deceased within $48 \mathrm{~h}$ after admission were analyzed regarding diagnoses from initial ER assessment, including MSCT, and diagnoses from autopsy. Data were prospectively collected and retrospectively analyzed. Autopsy reports were compared to diagnoses of ER assessment and MSCT. Missed diagnoses (MD) and missed potentially fatal diagnoses (MPFD) were analyzed.

Results Seventy-three patients with a mean age of 53.2 years were included into the study. Sixty-three percent were male. Autopsy revealed at least one missed

S. A. Euler

simon.euler@tirol-kliniken.at

1 Department of Trauma Surgery, Medical University Innsbruck, Anichstr. 35, 6020 Innsbruck, Austria

2 Department of Diagnostic \& Interventional Radiology, Hall Regional Hospital, Milserstr. 10, 6060 Hall in Tirol, Austria

3 Trauma Department, Hannover Medical School (MHH), Carl-Neuberg-Str. 1, 30625 Hannover, Germany diagnosis in $25 \%$ of the patients, with the thoracic area accounting for $67 \%$ of these. At least one MPFD was found in $4.1 \%$ of the patients, all of them being located in the thorax. Total numbers of MD and MPFD were significantly lower for the newer CT generation (64 MSCT, $N=11$ ), compared to older one (4 MSCT, $N=26$ ).

Conclusions As determined by autopsy, modern multislice computed tomography is an accurate method to diagnose injuries. However, $25 \%$ of all diagnoses, and $4.1 \%$ of potentially fatal diagnoses are still missed in trauma patients, who deceased within the first $48 \mathrm{~h}$ after admission. Therefore, autopsy seems to be necessary to determine potentially missed diagnoses for both academic and medicolegal reasons as well as for quality control.

Keywords Autopsy · CT scan · Emergency room · Missed diagnoses $\cdot$ Trauma

\section{Introduction}

Emergency room (ER) management of trauma patients has been evolving. In addition to the traditional diagnostic means of X-ray and sonography, multislice computed tomography (MSCT) has been established in many trauma centers worldwide. MSCT is recommended in ER assessment of hemodynamically stable patients [1-3]. Recent studies have shown its diagnostic superiority compared to the conventional assessment, including radiography and sonography [1, 3]. In fatal cases, autopsy is still considered to be the gold standard for assessing the cause of death though for both academic and medicolegal reasons [4-9]. However, some authors have stated that autopsy after modern ER assessment is no longer required [10]. 
The aim of this study was to compare the findings of complete initial ER and MSCT assessment to the findings during autopsy in patients not surviving the first $48 \mathrm{~h}$ after admission. We hypothesized that autopsy was more accurate than MSCT in diagnosing potentially fatal diagnoses.

\section{Patients and methods}

This study was approved by our institutional Ethical Committee. Between January 2004 and September 2007, all trauma patients undergoing ER treatment in our institution who deceased within $48 \mathrm{~h}$ after admission were analyzed regarding initial diagnoses from ER assessment including MSCT (including contrast medium), and diagnoses from autopsy. Two groups were defined due to an update of the CT scan to a newer generation in June 2006 (group 1: "generation 1 CT": LightSpeed Qx/I, GE, Milwaukee, USA; group 2: "generation 2 CT": GE LightSpeed VCT, GE, Milwaukee, USA). Patients who deceased prior to arrival in the ER, or who arrived under cardiopulmonary resuscitation (CPR), or who deceased more than $48 \mathrm{~h}$ after ER admission, were excluded. Only patients who received autopsy as well as complete standardized ER assessment, including complete MSCT scan of the head, neck, thorax, abdomen, pelvis, and obviously injured extremities, were included. If required, MSCT angiography for detection of vascular lesions, X-ray of the thorax following acute invasive interventions (central intravenous lines or drainages), and X-rays of injured extremities for pre-operative planning were added. All radiological diagnostics were performed by the particular senior radiologist on duty at the same time with the patient receiving the MSCT.

Data were prospectively collected and retrospectively analyzed. Autopsy reports were compared to diagnoses by ER assessment and MSCT, and missed diagnoses (MD) as well as missed potentially fatal diagnoses (MPFD) were analyzed. A senior expert radiologist analyzed whether MD and MPFD were caused by technical error, human error, or both.

Autopsy was performed in all patients by the department of Forensic Medicine or the department of Pathology of our institution. Autopsy findings were compared to the documented clinical data. The Injury Severity Score (ISS) was calculated for all patients. We primarily searched for MPFD, defined as injuries that raise the ISS and could independently have caused a fatal course of the patient. In patients with a MPFD, a new calculation of the adjusted ISS after autopsy was performed.

Statistic evaluation was performed using SPSS for Windows (SPSS, Chicago, Illinois). For specific indications, Wilcoxon test and for differences in arithmetic means and frequencies, Mann-Whitney, Chi-Quadrate, and Fisher's exact tests were used. The level of significance was defined as $p<0.05$.

\section{Results}

In total, 1916 trauma patients that underwent ER treatment were evaluated. The overall mortality within the first $48 \mathrm{~h}$ after admission was $4.5 \%$. In total, 73 patients with a mean age of 53.2 years were included into the study. Sixty-three percent were male.

Combining both groups, autopsy revealed at least one missed diagnosis in $25 \%$ of the patients, with the thoracic region accounting for $67 \%$ of these (Table 1). At least one MPFD was found in $4.1 \%$ of the patients, all of them being located in the thoracic region ( 2 aortic ruptures, 1 rupture of the inferior vena cava, Table 2). Total numbers of MD, and MPFD were significantly lower for group 2 (64 MSCT,

Table 1 Detailed list of all missed diagnoses

\begin{tabular}{|c|c|c|c|}
\hline Region & $\begin{array}{l}\text { Number } \\
(\%)\end{array}$ & $\begin{array}{l}\text { Group } 1 \\
(4 \text { slice } \\
\text { CT) }\end{array}$ & $\begin{array}{l}\text { Group } 2 \\
(64 \text { slice } \\
\text { CT) }\end{array}$ \\
\hline \multicolumn{4}{|c|}{ Head/neck/cervical spine $[N=6(18.2 \%)]$} \\
\hline Fracture of the cranium & 2 & 2 & \\
\hline Subarachnoidal bleeding & 1 & & 1 \\
\hline $\begin{array}{l}\text { Hemorrhagic contusion of the } \\
\text { cerebral cortex }\end{array}$ & 1 & 1 & \\
\hline $\begin{array}{l}\text { Avulsion of the ligamentary } \\
\text { unit btw. skull base and } \\
\text { cervical spine }\end{array}$ & 1 & & 1 \\
\hline Fracture of a cervical vertebra & 1 & 1 & \\
\hline \multicolumn{4}{|c|}{ Thorax/thoracic spine $[N=22(66.6 \%)]$} \\
\hline Fracture of ribs & 6 & 4 & 2 \\
\hline Pulmonary fat embolism & 4 & 4 & \\
\hline Aortic rupture & 2 & 1 & 1 \\
\hline $\begin{array}{l}\text { Rupture of the inferior vena } \\
\text { cava }\end{array}$ & 1 & 1 & \\
\hline Contusion of the heart & 3 & 1 & 2 \\
\hline Rupture of the diaphragm & 1 & 1 & \\
\hline $\begin{array}{l}\text { Central avulsion of the } \\
\text { pulmonary veins }\end{array}$ & 1 & & 1 \\
\hline Fracture of the sternum & 1 & 1 & \\
\hline $\begin{array}{l}\text { Luxation of the sterno- } \\
\text { clavicular joint }\end{array}$ & 1 & & 1 \\
\hline Avulsion of a main bronchus & 1 & 1 & \\
\hline Rupture of the pericardium & 1 & 1 & \\
\hline \multicolumn{4}{|c|}{ Abdomen/lumbar spine $[N=5(15.2 \%)]$} \\
\hline Rupture of the liver & 4 & 3 & 1 \\
\hline Renal rupture & 1 & 1 & \\
\hline Total & 33 & & \\
\hline
\end{tabular}


Table 2 Detailed summary of patients with $\operatorname{MPFD}(N=3)$

\begin{tabular}{|c|c|c|c|}
\hline & $\begin{array}{l}\text { Patient } 1 \text { (48 years; group 2; } 64 \\
\text { slice CT) }\end{array}$ & Patient 2 (78 years; group 1; 4 slice CT) & $\begin{array}{l}\text { Patient } 3 \text { (90 years; group 1; } 4 \text { slice } \\
\text { CT) }\end{array}$ \\
\hline Trauma & Blunt trauma (run over) & Blunt trauma (knocked down by a car) & Blunt trauma (run over) \\
\hline Course & $\begin{array}{l}\text { Hemodynamically unstable within } \\
\text { ER } \\
\text { Deceased after open thoracotomy } \\
\text { and reanimation }\end{array}$ & $\begin{array}{l}\text { Hemodynamically unstable within ER } \\
\text { Deceased shortly after MSCT }\end{array}$ & $\begin{array}{l}\text { Stable conditions at admission } \\
\text { Severe deterioration within } \\
\text { diagnostics } \\
\text { Deceased shortly after MSCT }\end{array}$ \\
\hline Diagnostics & Complete MSCT scan protocol & Complete MSCT scan protocol & Complete MSCT scan protocol \\
\hline Diagnoses in ER & $\begin{array}{l}\text { Multiple rib fractures } \\
\text { Tension pneumothorax } \\
\text { Bleeding from the right } \\
\text { pulmonary artery } \\
\text { Air in the right atrium and } \\
\text { ventricle }\end{array}$ & $\begin{array}{l}\text { Subdural and contusion hematoma, cerebral } \\
\text { edema, midline shift } \\
\text { Multiple rib fractures } \\
\text { Fractures of clavicle and scapula } \\
\text { Pneumothorax } \\
\text { Pelvic fracture (Type B) }\end{array}$ & $\begin{array}{l}\text { Subdural and subarachnoidal } \\
\text { hematoma, midline shift } \\
\text { Actively bleeding hematothorax } \\
\text { Rupture of kidney } \\
\text { Actively bleeding pelvic fracture } \\
\text { (Type C) }\end{array}$ \\
\hline Therapy & $\begin{array}{l}\text { Chest drainage } \\
\text { Massive blood transfusion } \\
\text { Open thoracotomy and CPR }\end{array}$ & CPR & CPR \\
\hline $\begin{array}{l}\text { Missed potential fatal } \\
\text { diagnoses }\end{array}$ & $\begin{array}{l}\text { Incomplete rupture of aorta (loco } \\
\text { typico) } \\
\text { Central tear of pulmonary vein } \\
\text { Rupture of Vena cava inferior } \\
\text { Rupture of liver and kidney }\end{array}$ & $\begin{array}{l}\text { Rupture of inferior vena cava } \\
\text { Rupture of pericardium } \\
\text { Rupture of liver }\end{array}$ & Rupture of descendent aorta \\
\hline
\end{tabular}

Table 3 MD and MPFD—nature of errors (absolute numbers; some patients did have two or more MD/MPFD, and human/technical errors occurred simultaneously in some cases)

\begin{tabular}{|c|c|c|c|c|c|c|c|c|c|}
\hline & Overall & Group 1 & Group 2 & $\begin{array}{l}\text { Overall } \\
\text { technical error }\end{array}$ & $\begin{array}{l}\text { Group } 1 \\
\text { technical error }\end{array}$ & $\begin{array}{l}\text { Group } 2 \\
\text { technical error }\end{array}$ & $\begin{array}{l}\text { Overall } \\
\text { human error }\end{array}$ & $\begin{array}{l}\text { Group } 1 \\
\text { human error }\end{array}$ & $\begin{array}{l}\text { Group } 2 \\
\text { human error }\end{array}$ \\
\hline MD & 34 & 24 & 10 & 16 & 15 & 4 & 15 & 9 & 6 \\
\hline MPFD & 3 & 2 & 1 & 3 & 2 & 1 & 2 & 1 & 1 \\
\hline
\end{tabular}

$N=11$ ), compared to group 1 (4 MSCT, $N=26$ )

(Table 3). Total numbers of MD and MPFD for each group as well as the distribution of human/technical errors are displayed in Table 3.

There was no difference of ISS between the status after ER and MSCT assessment (median ISS 24) and the adjusted status following autopsy (median ISS 25).

\section{Discussion}

The most important finding of this study was that multislice computed tomography missed at least one diagnosis in $25 \%$, and at least one potentially fatal diagnosis in $4.1 \%$, as determined by autopsy in trauma patients not surviving the first $48 \mathrm{~h}$ after admission. $67 \%$ of the missed diagnoses and $100 \%$ of the potentially fatal diagnoses were located in the thoracic region. Total numbers of MD and MPFD were significantly lower for the newer CT generation (64 MSCT, $N=11$ ), compared to older one (4 MSCT, $N=26$ ). The time period of $48 \mathrm{~h}$ until decease of the patient as inclusion criterion for the study was chosen to exclude secondary potentially fatal complications, such as pneumonia, SIRS, sepsis, organ dysfunction or MODS as possible confounding factors.

Our demographic data were in accordance with the previous reported cohorts. Fung Kon Jin et al. quote a number of 16 patients in one year (trauma, autopsy, at least partial diagnostic assessment but variable times of death after admission) [11]. Sharma et al. included 160 patients in four years (trauma, autopsy, death within $24 \mathrm{~h}$, at least partial diagnostics but also patients admitted under CPR or already dead) [7]. The average age (53.16 years) and distribution of gender ( $63 \%$ male) of our cohort also matches the values of comparable studies $[4,11,12]$.

In our cohort, $4.4 \%$ of all trauma patients admitted over the ER did not survive the first $48 \mathrm{~h}$ in hospital. Compared to previous studies, this is a quite low value. Matthes et al. found an early lethality within the first $24 \mathrm{~h}$ of $8.7 \%$ in severely injured patients [13]. Other authors found an early 
lethality of 46 through $61 \%$ within the first $48 \mathrm{~h}$ $[4,7,10,12]$. Differences in definitions used for "trauma" among the various studies consequently lead to different selection criteria for eligible patients.

The incidence of all missed diagnoses in our study was $25 \%$. In other studies, the incidence ranges from $0 \%$ (Forsythe et al. [10]) to 57.6\% (Sharma et al. [7]). Different autopsy rates in many studies, differences in quality, regulations of accuracy and requested exploration may be reasons for the discrepancies. Furthermore, the definition of a missed diagnosis varies. Many authors only included severe MD or MPFD [7, 10]. The MPFD rate in this study was $4.1 \%$. Reported rates of MPFD range from 0 to $14 \%$ $[4,7,8,12]$.

Injuries of the thorax represented the area with the majority of MD (66.6\%), followed by head/neck (18.2\%), and abdomen/pelvis/extremities (15.2\%). This corresponds well to quotes in prior studies [4, 12].

Secondary complications and comorbidities were not counted as MD. During autopsy, venous thrombosis of the sinus was found in five patients as a diagnosis not known before. This diagnosis was valued as secondary complication and thus not counted as a MD. Nevertheless, diagnoses like bronchopneumonia and severe haemorrhage are dedicated to be the most common MD in trauma patients [4, 7].

Reasons for missing a diagnosis by means of MSCT scan are numerous, including a variety of human and technical errors. While human errors appear to be more or less constant and independent from the resolution of the CT scanner, technical errors appear to be reducible by sufficient image thickness and image intervals. In the particular setting of hemodynamically unstable patients, insufficient circulation patterns may compromise the distribution of injected contrast medium and accordingly the detection of active bleeding injuries.

As for the survey of the ISS, severities of traumas were reflected in the identified values. After autopsy, we did not find a significant change of the ISS (median ISS 24 before, and 25 after autopsy). Hodgson et al. reports an increase from 30 to 43 in trauma patients after autopsy [8]. Other authors describe an increased ISS after autopsy in 7-69\% of all patients [12, 14].

The question whether MSCT is accurate enough to replace autopsy is of particular interest. In 2007, Molina et al. conducted a study on 113 trauma patients who obtained a CT scan within $24 \mathrm{~h}$ before death and who finally underwent autopsy [15]. They found unacceptably low rates of sensitivity and specificity as well as positive and negative predictive values for MSCT. This study distinctly challenges the idea of post mortem CT diagnostics, particularly in the forensic area. However, it has to be considered that this study was conducted between 2002 and 2005, using CT scanners with image thickness of 5-10 mm at 5-to-10-mm intervals for the skull, 3-mm image thickness at a $2-\mathrm{mm}$ interval for the cervical spine, and 5-mm image thickness at a 5-mm interval for the chest, abdomen, and pelvis. This makes their findings comparable to our group 1 and illustrates the impact of high-resolution CT scans with sufficient slice thickness and slice intervals on diagnostic accuracy. Our results suggest that the rate of technical errors can be reduced by using a 64 MSCT scanner compared to the older 4 MSCT scanner.

This study has several limitations. First, only missed diagnoses offering a direct relation to the causative trauma were considered. Second, MSCT scan was done in some patients with insufficient circulation patterns, which made it impossible to exactly evaluate the distribution of injected contrast medium and accordingly to detect all active bleeding injuries. Third, due to the retrospective study design and partially insufficient documentatione.g., imaging from external referring hospitals or lost records, we were not able to fully report all missed diagnoses on all patients. 32 patients had to be excluded for this reason.

\section{Conclusions}

As determined by autopsy, modern multislice computed tomography is an accurate method to diagnose injuries. However, $25 \%$ of all diagnoses, and $4.1 \%$ of potentially fatal diagnoses are still missed in trauma patients, who deceased within the first $48 \mathrm{~h}$ after admission. Therefore, autopsy seems to be necessary to determine potentially missed diagnoses for both academic and medicolegal reasons as well as for quality control.

Acknowledgements Open access funding provided by University of Innsbruck and Medical University of Innsbruck.

Open Access This article is distributed under the terms of the Creative Commons Attribution 4.0 International License (http://crea tivecommons.org/licenses/by/4.0/), which permits unrestricted use, distribution, and reproduction in any medium, provided you give appropriate credit to the original author(s) and the source, provide a link to the Creative Commons license, and indicate if changes were made.

\section{References}

1. Huber-Wagner S, Lefering R, Qvick LM, Körner M, Kay MV, Pfeifer KJ et al. (2009) Effect of whole-body CT during trauma resuscitation on survival: a retrospective, multicentre study. Lancet 25 373(9673):1455-1461

2. Rieger M, Czermak B, El Attal R, Sumann G, Jaschke W, Freund M (2009) Initial clinical experience with a 64-MDCT whole-body scanner in an emergency department: better time management and diagnostic quality? J Trauma 66(3):648-657 
3. Rieger M, Sparr H, Esterhammer R, Fink C, Bale R, Czermak B et al (2002) Modern CT diagnosis of acute thoracic and abdominal trauma. Anaesthesist 51(10):835-842 (Review. German)

4. Barendregt WB, de Boer HH, Kubat K (1993) Quality control in fatally injured patients: the value of the necropsy. Eur J Surg 159(1):9-13

5. Goldman L, Sayson R, Robbins S, Cohn LH, Bettmann M, Weisberg M (1983) The value of the autopsy in three medical eras. N Engl J Med 308(17):1000-1005

6. Hodgson NF, Stewart TC, Girotti MJ (2000) Autopsies and death certification in deaths due to blunt trauma: what are we missing? Can J Surg 43(2):130-136

7. Sharma BR, Gupta M, Harish D, Singh VP (2005) Missed diagnoses in trauma patients vis-a-vis significance of autopsy. Injury 36(8):976-983

8. Stothert JC Jr, Gbaanador GB, Herndon DN (1990) The role of autopsy in death resulting from trauma. $\mathrm{J}$ Trauma 30(8):1021-1026

9. Steinwall D, Befrits F, Naidoo SR, Hardcastle T, Eriksson A, Muckart DJ (2012) Deaths at a Level 1 Trauma Unit: a clinical finding and post-mortem correlation study. Injury 43(1):91-95
10. Forsythe RM, Livingston DH, Lavery RF, Mosenthal AC, Hauser CJ (2002) Autopsies in trauma do not add to peer review or quality assurance. J Trauma 53(2):321-325

11. Fung Kon Jin PH, Klaver JF, Maes A, Ponsen KJ, Das C, Goslings JC (2008) Autopsies following death due to traumatic injuries in The Netherlands: an evaluation of current practice. Injury 39(1):83-89

12. Ong AW, Cohn SM, Cohn KA, Jaramillo DH, Parbhu R, McKenney MG et al (2002) Unexpected findings in trauma patients dying in the intensive care unit: results of 153 consecutive autopsies. J Am Coll Surg 194(4):401-406

13. Matthes G, Seifert J, Ostermann PA, Wurfel S, Ekkernkamp A, Wich M (2001) Early death of the severly injured patient-a retrospective analysis. Zentralbl Chir 126(12):995-999

14. Streat SJ, Civil ID (1990) Injury scaling at autopsy: the comparison with premortem clinical data. Accid Anal Prev 22(3):241-252

15. Molina DK, Nichols JJ, Dimaio VJ (2007) The sensitivity of computed tomography (CT) scans in detecting trauma: are CT scans reliable enough for courtroom testimony? J Trauma 63(3):625-629 